\title{
Physical Education in the COVID Era: Considerations for Online Program Delivery Using the Comprehensive School Physical Activity Program Framework
}

\author{
Collin A. Webster \\ University of South Carolina
}

Jaimie McMullen

University of Northern Colorado

\author{
Emily D'Agostino \\ Duke University
}

\author{
Brian Culp \\ Kennesaw State University \\ Chad Killian \\ Georgia State University
}

\author{
Mark Urtel \\ Indiana University-Purdue University \\ Indianapolis
}

Cate A. Egan Loiacono
University of Idaho

In the wake of COVID-19, online physical education (OLPE) has become essential to the sustainability of school physical education programs. The purpose of this article is to consider factors that may be influential in efforts to deliver OLPE to students. The comprehensive school physical activity program model is used to frame a multicomponent conceptualization of OLPE and its goals and outcomes. Central to this framing is the intersectionality of school physical education, the family, and the community. This article provides a platform for physical education teacher educators and researchers to advance OLPE in its support of both the educational and public health benefits of high-quality physical education programs.

Keywords: CSPAP, family and community engagement, online physical education, physical education standards, public health

The rapid and inexorable worldwide spread of SARS-CoV2-the coronavirus which causes the disease known as COVID-19 - presents physical education professionals with new and unforeseen challenges related to program delivery. Campus closures due to the pandemic created an urgent need, in $\mathrm{P}-12$ schools and institutions of higher education, to consider available alternatives to in-person programming. Most notably, online physical education (OLPE), which previously stood in the periphery of the field's vision (Daum \& Woods, 2015), is now a subject of central focus. OLPE has the ability to offer the swift response needed in the context of COVID-19. OLPE is not only a potential solution to a problem, but also part of a growing presence in education, marked by the increasing viability of virtual alternatives to brick and mortar classrooms and in-person instruction. Distance education and online learning have been gaining momentum in recent years (Digital Learning Collaborative, 2020; Evergreen Education Group, 2016; Kooiman, 2017), and technologies, such as virtual reality and

\footnotetext{
Webster is with the Department of Physical Education, University of South Carolina, Columbia, SC, USA. D'Agostino is with the Department of Family and Community Health, Duke University, Durham, NC, USA. Urtel is with the Department of Kinesiology, Indiana University-Purdue University Indianapolis, Indianapolis, IN, USA. McMullen is with the School of Sport and Exercise Science, University of Northern Colorado, Greeley, CO, USA. Culp is with the Department of Health Promotion and Physical Education, Kennesaw State University, Kennesaw, GA, USA. Egan Loiacono is with the Department of Movement Sciences, University of Idaho, Moscow, ID, USA. Killian is with the Department of Kinesiology and Health, Georgia State University, Atlanta, GA, USA. Webster (websterc@mailbox.sc.edu) is corresponding author.
}

artificial intelligence, offer new possibilities for education. The present pandemic has merely punctuated the need to explore integrating such innovations into 21st century teaching and learning.

At face value, OLPE conveys oxymoronic qualities (Buschner, 2006; Kooiman, 2017; Mohnsen, 2012) and, at first regard, may generate skepticism. Certainly, OLPE is not without issues, perhaps the most prominent of which is that it lacks evidence-based best practices (Kooiman, 2017). With the advent of the Internet and its implications for education, Locke (1997) warned physical educators to avoid technological determinism, which he defined as the "mental state in which one feels compelled to invest money, time, and emotional energy in a gadget on the basis of predictions about the benefits it will bring - in the absence of any empirical evidence that it reliably will do so" (p. 272). Similarly, Buschner (2006), cautioned that without good, evidence-based teaching practices, "OLPE is still only a box that includes sophisticated sound, lights, images, and words that purport to help students learn about and be physically active - but it is not physical education in its present form" (p. 5). The Society of Health and Physical Educators (SHAPE) America (2018) asserts that physical education that is delivered online should share the same purpose and intended outcomes as traditional, in-person physical education. Daum (2020) further contends that OLPE bears the same responsibilities as traditional programs with respect to delivering equitable, developmentally appropriate, and equally accessible learning experiences.

While honorable, the high aspirations for OLPE should be viewed in light of what traditional, in-person physical education programs have been able to accomplish. It must be recognized that traditional programs struggle to meet the previously mentioned 
expectations for physical education. In the United States, the majority of students attending in-person physical education are likely not achieving the national content standards for K-12 learners (Hastie, 2017). In addition, although SHAPE America (2015) recommends that students engage in vigorous or moderate physical activity during at least $50 \%$ of physical education class time, this benchmark often eludes physical education programs that use conventional, face-to-face instruction (Hollis et al., 2016, 2017). Finally, traditional physical education has faced challenges related to equity and access, such as language barriers, funding limitations, and inadequate physical spaces for participation (Lawson, 2018). An important question at this critical juncture in the evolution of the profession is whether OLPE can be optimized in ways that leverage the efficacy and impact of in-person physical education programs for diverse communities and settings. Notably, a body of evidence already exists to suggest that, when supported with appropriate pedagogical practices, digital technologies, such as social media, blogs, video analysis, and video games, can be effectively integrated into physical education to enhance students' learning (Bodsworth \& Goodyear, 2017; Casey, Goodyear, \& Armour, 2017). Moreover, findings from a recent study found that high school students enrolled in online health and physical education had more favorable perceptions of their learning experience (e.g., teacher feedback and responsiveness, understanding and interest related to the content, and perceived health gains) compared with students enrolled in in-person programs (Williams, Martinasek, Karone, \& Sanders, 2020).

\section{Comprehensive School Physical Activity Program Framework}

The OLPE learning environments, both traditionally and in the current climate, expand beyond the walls of the school gym and are most likely to be circumscribed within home- and community-based settings (SHAPE America, 2018). A relevant framework for conceptualizing, researching, and applying best practices in expanding physical education to multiple school- and community-based settings is the comprehensive school physical activity program (CSPAP) model (Figure 1; Centers for Disease Control and Prevention [CDC], 2019). The CSPAP model is the CDC's (2019) national framework for physical education and physical activity of school-aged youth in the United States. According to SHAPE America (2015), the purpose of a CSPAP is for school systems to identify and use available assets, through a coordinated and synergistic approach, to achieve three goals: (a) provide quality physical education for all students, (b) increase all students' practice opportunities for skills learned in physical education, and (c) help all children and adolescents achieve the nationally recommended 60 min of physical activity each day for optimal health (U.S. Department of Health and Human Services, 2018). Thus, within an equity and inclusion lens, the intent of a CSPAP is to ensure both the physical education and physical activity needs of every student are addressed.

CSPAPs have gained significant traction across the globe in research and professional recommendations related to youth physical activity promotion (Carson \& Webster, 2020). Yet, the evidence base for CSPAPs is still young, and existing CSPAP research is mostly devoted to investigating the effectiveness of individual CSPAP components in increasing youth physical activity engagement (Goal c). Even though physical education is conceptualized as the cornerstone of a CSPAP (CDC, 2019; SHAPE America, 2015), little CSPAP research has investigated how a CSPAP or its various components can be used to help physical education meet national



Figure 1 - Comprehensive school physical activity program framework (CDC, 2019).

recommendations (Goal a) or to promote expanded physical education learning opportunities (Goal b). Furthermore, the family and community engagement component of the model remains one of the least studied in terms of addressing any of the previously mentioned goals of a CSPAP (Chen \& Gu, 2018). This is surprising, given that the noted importance of families and communities in affecting the education of the youth traces back more than a century ago to the work of Dewey (1916), who first made clear the impact of human association, in the form of family and society, on the education, socialization, and development of children.

Research on the use of online instruction in physical education is in its nascent stages despite consistent calls for comprehensive study (Daum \& Buschner, 2014; 2018; Killian, Kinder, \& Woods, 2019). As a result, current understanding related to the ability of OLPE to promote physical education and physical activity through family and community engagement is limited. In the present article, the authors link OLPE to the conceptual basis for CSPAP-driven efforts that directly support a school's physical education program and its intended learning outcomes. Specifically, a schematic is introduced to elucidate the interconnectedness between the school, the digital divide, physical education, the family, the community, and the student to highlight factors that might warrant consideration in OLPE research and practice. This article is intended to guide the efforts of physical education teacher educators and researchers to optimally prepare a wide range of end users (e.g., preservice teachers, $\mathrm{P}-12$ school professionals, parents, and community leaders) for the new reality in which OLPE is a necessary tool for physical education program effectiveness.

\section{Using OLPE to Support the Goals of a CSPAP}

Based on the idea that OLPE can meaningfully contribute to both the physical education- and public health-aligned goals of a 
CSPAP, it is important to clearly illustrate how OLPE might be used to support these goals. In particular, teacher educators and researchers can benefit from conceptualizations of OLPE as an integrated part of the CSPAP framework. Such conceptualizations can help teacher educators organize professional preparation experiences for preservice and in-service teachers and guide researchers' lines of inquiry and intervention programming. The schematic in Figure 2 was designed with these purposes in mind, based on literature spanning (a) issues of equity and inclusion in online learning (e.g., Basham, Stahl, Ortiz, Rice, \& Smith, 2015; Centeio, 2017; Huerta, Shafer, Barbour, Miron, \& Gulosino, 2015), (b) OLPE (e.g., Harris \& Metzler, 2019; Killian et al., 2019; Mosier \& Lynn, 2012), (c) family and community engagement to support physical education and physical activity for schoolaged youth (e.g., Brown, Atkin, Wong, Chinapaw, \& van Sluijs, 2016; Cipriani, Richardson, \& Roberts, 2012; Egan \& Miller, 2019), and (d) recommendations related to family and community partnerships (e.g., Allar et al., 2017; Epstein, 2010; Kruger et al., 2012). The schematic is divided into four parts: the CSPAP conceptual framework, the digital divide, the OLPE support system, and the CSPAP outcomes framework. Within each part, factors that may be influential in efforts to support the goals of a CSPAP through OLPE are listed. Each part of the schematic is discussed in detail within the following sections of this article.

\section{The CSPAP Conceptual Framework}

As previously stated, the goals of a CSPAP are to (a) provide quality physical education for all students, (b) increase all student's physical education skills through additional practice opportunities, and (c) help all students accumulate at least 60 min of physical activity each day (SHAPE America, 2015). Two CSPAP components - physical education and family and community engagement - are highlighted in the schematic to suggest that each of these components has an essential role to play in delivering OLPE that extends and reinforces students' physical education learning and physical activity engagement. Given that OLPE is contextualized within the family and community settings, family and community engagement is an important lever for physical education programs to succeed in reaching their educational goals. Likewise, bringing physical education to students' homes and communities can provide an outlet for physical activity participation. Webster, Rink et al. (2020) underscore the idea that the different CSPAP components should work synergistically in mutually reinforcing ways such that physical activity opportunities across a CSPAP enhance students' physical education learning, while physical education learning concurrently enhances students' physical activity participation. This proposition embraces the possibility that meaningful connections can be established between physical education, the broader school environment, and what Kirk (1999) refers to as "physical culture," which he defines as "a range of practices concerned with the maintenance, representation and regulation of the body centred on three highly codified, institutionalized forms of physical activity - sport, physical recreation and exercise" (p. 65). The link between physical education learning and wider physical activity participation may not always be clear to students or made explicit by teachers (Parker, MacPhail, O'Sullivan, Ní Chróinín, \& McEvoy, 2018). Therefore, highlighting the potential for CSPAPs to synergistically bolster students' physical activity levels and physical education learning is important to informing the way OLPE is designed and implemented as part of broader CSPAP initiatives.

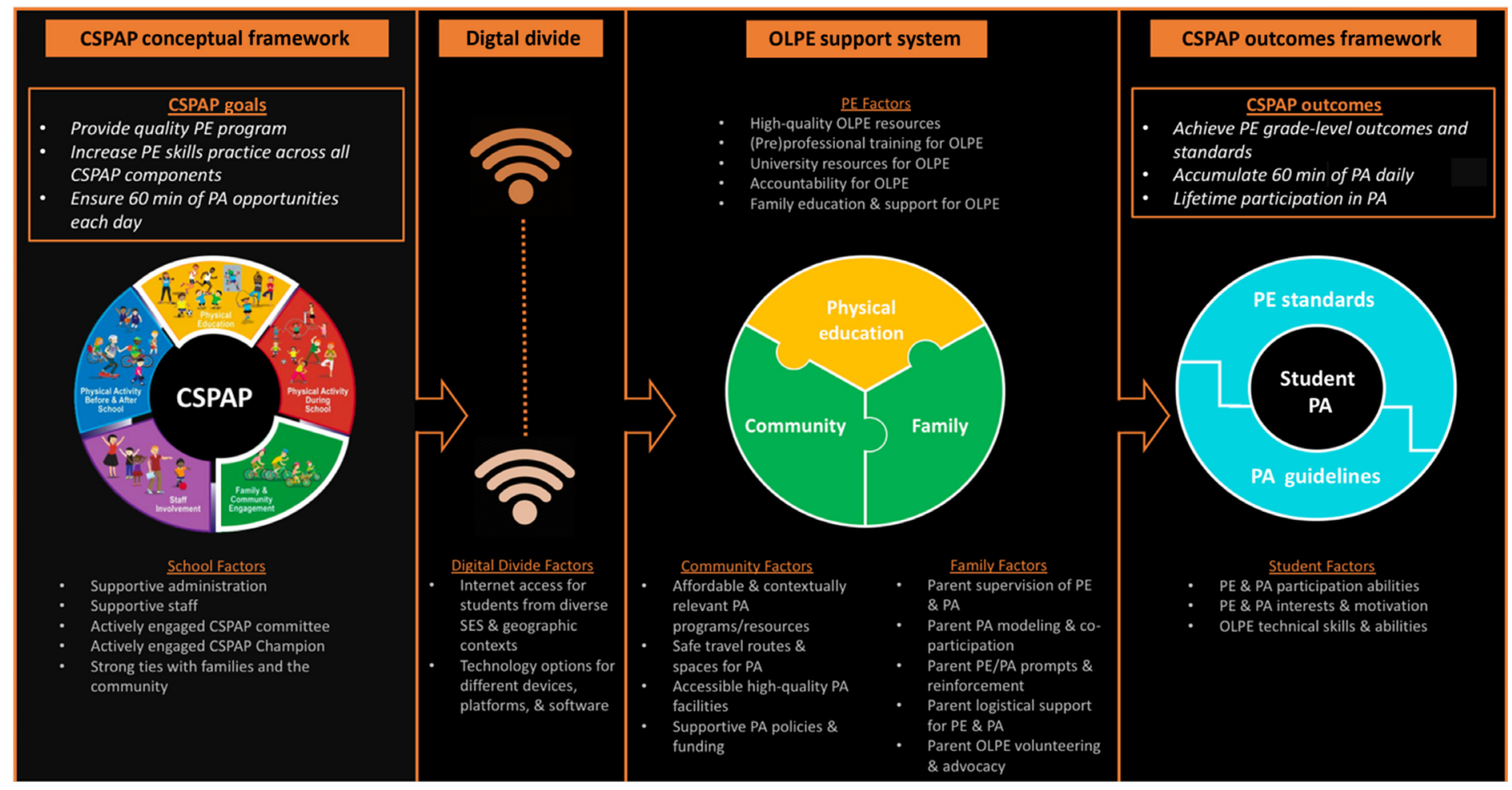

Figure 2 - Schematic depicting the goals and projected outcomes of a CSPAP when it is supported using OLPE that addresses key factors specific to the school, the digital divide, physical education, the family, the community, and the student. CSPAP = comprehensive school physical activity program; $\mathrm{OLPE}=$ online physical education; $\mathrm{PA}=$ physical activity; $\mathrm{PE}=$ physical education; $\mathrm{SES}=$ socioeconomic status. 
In Figure 2, the factors identified for consideration within the CSPAP conceptual framework are those related to the school in general, as other factors specific to physical education, the family, and the community are identified within the OLPE support system, which focuses on these CSPAP components. School-based factors that could be influential in the extent to which a CSPAP, or any of its components, are successfully implemented include a supportive administration, a supportive staff, an actively engaged CSPAP committee, an actively engaged CSPAP champion, and strong ties with the family and the community. Carson, Castelli, Beighle, \& Erwin (2014) proposed a conceptual model for CSPAP research and practice in which they considered school administrators, a CSPAP committee, and a CSPAP champion to be leaders in the implementation of CSPAPs. Although limited research exists on the influence of these potential change agents in CSPAP adoption or sustainability, Webster, Glascoe et al. (2020) discussed three themes in the recommendations for school administrators' involvement in school-based health promotion programs. These included collaboration (e.g., involvement in planning and programming); advocacy (e.g., policy involvement); and support (e.g., professional development and technical assistance). In addition, researchers (Orendorff et al., 2020) found that intrapersonal variables, such as expected outcomes of a CSPAP, directly predicted school principals' selfreported CSPAP involvement, while interpersonal (e.g., parent and teacher support for CSPAPs) and environmental variables (e.g., overall school, community, and policy support for CSPAPs) indirectly predicted such involvement. These findings highlight not only the importance of administrative support in promoting a CSPAP, but also the importance of strong working relationships among school professionals and also between the school, families, and the local community in bringing a CSPAP to fruition.

\section{The Digital Divide}

Positioned between the CSPAP conceptual framework and the OLPE support system within the schematic is the digital divide, particularly the Internet, through which OLPE is made possible. The digital divide represents the idea that the division of technologies, and consequently the extent to which OLPE can be accessed, plays a mediating role in the success of OLPE. Although numerous kinds of technology used in physical education, such as heart rate and activity monitors, are important to consider with respect to the digital divide, access to high-speed Internet is essential to the successful delivery of OLPE. However, such access is not a given for all students (Centeio, 2017). Issues of Internet access can be understood in terms of sociocultural, geographic, and technical aspects of the digital divide. Students from low-income families likely have fewer resources (e.g., sufficient Internet connectivity for extended online learning) to support their success learning online when compared with students of high-income families (Fishbane \& Tomer, 2020; The Foundation for Blended and Online Learning, 2018), and low-income students do not appear to be accessing online programs at the same rates as their more financially secure peers (Huerta et al., 2015). When school campuses closed due to COVID-19, 35\% of low-income U.S. households with school-aged children did not have a high-speed Internet connection at home compared with $15 \%$ of all U.S. households with school-aged children (Pew Research Center, 2020). In rural areas, students may experience issues of access due to lack of Internet access and the inconsistency of broadband speed during peak usage times (Riddlesden \& Singleton, 2014). Also, from a technical perspective, disparities may exist between the types of devices, platforms, and software that are used in students' homes. Differences in devices used may be based on a family's income status. For instance, individuals from low-income households are more likely to access the Internet from a smartphone than from a computer (Smith, 2015), and this could impact the extent to which students are able to use all features of an online learning platform.

Overall, there is little research on equity issues related to online learning, and it is challenging to fully consider the many variables that could be associated with Internet access and use (Rose, 2014; Rose \& Blomeyer, 2007). However, Rose (2014) and Rose and Blomeyer (2007) highlight issues that should be given attention, including inequitable access to reliable, high-speed Internet connections, support for special needs students and students with disabilities, and awareness of difference in treatment/discrimination based on gender, race/ethnicity, and cultural differences. All students require equitable access to content and instruction regardless of gender, race/ethnicity and cultural background, devices and high-speed connections, disabilities accommodations. A recent study suggests that barriers to equity and accessibility exist in OLPE (Killian, Woods, Graber, \& Templin, 2020). At a minimum, OLPE must account for what families can afford with respect to the costs of existing Internet options, what access restrictions exist due to the geographic locations of students' homes, and how students are most likely to access the Internet (i.e., via different devices, platforms, and software options).

\section{The OLPE Support System}

When students can access OLPE, they gain physical education and physical activity experiences through the OLPE support system. This system is conceptualized in the schematic as a coalition of school physical education, the family, and the community. Factors that warrant consideration within the OLPE support system include physical education factors, family factors, and community factors.

Physical education factors. Notwithstanding a few exceptions, such as the Online Physical Education Network (OPEN; openphysed.org), high-quality OLPE resources are scarce (Daum \& Buschner, 2014). For OLPE to align with and support standardsbased physical education and daily physical activity for students, it must capitalize on existing quality controls and affordances that make the traditional, in-person school environment attractive for physical education and physical activity programming, particularly as conceptualized using the CSPAP framework. Specifically, the advantages of public education are that it reaches virtually all children and adolescents, fosters an unparalleled environment for providing physical activity opportunities for all youth, and benefits from professional educators at relatively little financial cost to families. Thus, OLPE has the best chance to succeed in meeting the educational and public health-aligned goals of physical education when delivered through school systems, which provide the infrastructure for designing, developing, and delivering OLPE resources that meet the needs of every student.

While capitalizing on the advantages of school systems, OLPE will also likely need to work through many of the same challenges encountered in efforts to provide quality in-person physical education and physical activity promotion through CSPAPs (Webster, Beets, Weaver, Vazou, \& Russ, 2015). These challenges include a lack of in-service and preservice training devoted to developing teachers' competencies in OLPE design/delivery, a lack of research evidence to inform best practices in in-service and preservice teacher preparation related to OLPE, a lack of external accountability for providing quality OLPE through either policy or 
professional standards, and the possible reluctance of physical educators to embrace OLPE. Physical education professionals must become advocates for OLPE through increased attention to the topic in teacher education and research, as well as increased engagement with national organizations (e.g., SHAPE America), to build momentum and establish consensus frameworks for quality OLPE (Daum, 2020; Killian et al., 2019; Mosier \& Lynn, 2012). Despite how physical educators might have felt about OLPE in the past, COVID has created a need for the field to actively pursue OLPE-related research and scholarship and for the profession to embrace OLPE as an essential component of professional learning, standards, and accountability.

Physical educators must also play leading roles in providing the education and support families need to be effective in assisting with OLPE. Based on a review of 66 records, Henderson and Berla (1994) noted that enhancing the ways families and community could support student achievement involved first informing families of the content standards and then encourage parents to sit on the school standards teams; typically, where implementation and assessment conversations take place. In addition to educating parents about the subject matter standards, teachers should also keep parents apprised of local physical activity opportunities and help parents monitor family physical activity participation (Cipriani et al., 2012; Egan \& Miller, 2019; McWilliams, Bulger, Keath, \& Elliott, 2020). The promotion of physical activity among family members has also been found to be a strong predictor of students' physical activity levels (Glowacki, Centeio, Van Dongen, Carson, \& Castelli, 2016). Further guidance for teachers can be found from the CDC (2012), which suggests (a) creating opportunities for parents to share important aspects of their health needs related to culture, (b) translating health information into different languages, (c) helping parents set expectations for appropriate healthy behavior, (d) monitoring and modeling healthy behavior, (e) praising and rewarding desirable behaviors, and (f) understanding child development.

It is crucial for physical educators to acknowledge and appreciate the situational barriers that often prevent parents' engagement. Brown et al. (2016) identify numerous contextual factors that should be taken into consideration, such as family constraints (e.g., lack of time and scheduling difficulties); cultural relevance (e.g., the extent to which the curriculum aligns with family/ community contexts); and the family psychosocial environment (e.g., child-parent relationships). Physical education teachers can align their support for parent involvement according to specific situational barriers (Brown et al., 2016). For example, this might involve assisting with goal setting and providing positive reinforcement for families who face time-related challenges to engage in OLPE, or including activities designed for child-parent coparticipation in cases where family relationship building is identified as a key facilitator to youth physical activity. In the COVID era, as OLPE has entered the mainstream for physical education teachers, it has become increasingly clear that an awareness of home-based situational factors and contextual barriers that need to be addressed for programming to succeed for every student is often lacking.

Family factors. One of the major changes brought on by COVID19 is the environment where students receive their education. Children and adolescents have spent more time at home due to school campuses closing, stay-at-home orders, and quarantining. This change may be negatively influencing youth physical activity (Velde et al., 2020; Xiang, Zhang, \& Kuwahara, 2020). For example, researchers in The Netherlands found that since the onset of the pandemic, the number of children who were physically active at least $60 \mathrm{~min}$ per day decreased from $64 \%$ to $20 \%$ (Velde et al., 2020). Accordingly, pronounced attention to families as a key asset in supporting OLPE may be warranted in the COVID era. Families play an important role in influencing physical activity habits and providing opportunities for physical activity in youth (Erwin, Beighle, \& Castelli, 2013; Rhodes et al., 2020). In particular, there has been much research on the engagement of parents in their children's lifestyle habits, including physical activity (Lindsay, Sussner, Kim, \& Gortmaker, 2006). Although some questions need further investigation, such as whether a parent's gender or a child's age are significant factors in the effectiveness of a parent's efforts to promote physical activity (e.g., Anderson, Hughes, \& Fuemmeler, 2009; Davison, Jurkowski, Li, Kranz, \& Lawson, 2013; Kimiecik \& Horn, 1998; Moore et al., 1991; Pérusse, Leblanc, \& Bouchard, 1988; Sallis, Patterson, Buono, Atkins, \& Nader, 1988) and how parents might best support OLPE learning outcomes, it is clear that parents are integral to the success of efforts to promote physical education learning and increase youth physical activity at home and in the community (Lane et al., 2020).

The absence of adult supervision during students' physical activity participation has been noted as a limitation of OLPE (Harris \& Metzler, 2019; Mosier \& Lynn, 2012). Parents who maintained consistent communication with the OLPE instructor and provided support by monitoring students' physical activity to ensure accountability were identified as keys to success in an OLPE course (Kane, 2004). Research also suggests that parenting practices, such as modeling physically active behavior (Hutchens \& Lee, 2018), prompting children to be physically active, and engaging in physical activity with children, can increase children's physical activity levels (Lindsay, Wasserman, Muñoz, Wallington, \& Greaney, 2018; Ransdell et al., 2003) and similarly may serve to promote child physical activity in an OLPE context.

Other factors that may influence the extent to which OLPE can support the goals of a CSPAP are parent logistical support for children's OLPE and daily physical activity engagement, and parent volunteering and advocacy for OLPE. Examples of logistical support include scheduling time to assist students with OLPE assignments, providing transportation to physical activity facilities, and purchasing physical activity equipment when needed. With respect to volunteering and advocacy, parents might consider serving as ambassadors for students' OLPE learning and physical activity participation. Some ways to do this could be to serve as volunteer mentors, coaches, or tutors, or to share personal experiences and insights related to promoting children's OLPE learning and physical activity with school staff and community members (CDC, 2012). Overall, the abrupt transition to home-based learning for students during the COVID-19 pandemic has undoubtedly disrupted the lives of families in numerous ways and placed new burdens on parents and guardians. It would be unrealistic to expect families to engage in the previously mentioned strategies (i.e., participate with children in physical activity, supervise children's physical education learning and physical activity, provide logistical support, volunteer to support physical education, and advocate for physical education) without careful planning related to the investment of time and other resources (e.g., money needed to cover the costs of logistical support). Research is needed to better understand how families are coping during COVID-19, whether parents/guardians who have never participated in distance learning are able to support their children's at-home physical education, and what support strategies parents/guardians enact with the most success. 
Community factors. Community engagement involves integrating and identifying resources and services in the community to strengthen parent and school resources and programs (Epstein, 2010). Partnerships with community members allow schools to maximize their resources (e.g., funding and facility usage; Institute of Medicine, 2013). Community partnerships may include parks and recreation departments, health departments, or agencies (Erwin et al., 2013). Like the family, community engagement in OLPE and physical activity promotion for youth comes in multiple forms. These include space, programs, policies, and funding that support youth physical activity. Community spaces for physical activity encompass both the natural (e.g., green space, lakes, and mountains) and the built environment (e.g., safe routes for active travel, parks, playgrounds, community centers, and neighborhood streets). Community programs (e.g., after school programs and summer camps) can be hosted in a wide range of settings, such as school campuses, parks and recreation centers, faith-based organizations, and homes. Public policy and funding for youth physical activity are often intertwined, as policies can shape funding priorities.

Efforts to provide high-quality OLPE must include consideration for disparities among communities in relation to available, accessible, affordable, and contextually relevant activity spaces, programs, and policies/funding. Collaboration with local agencies and organizations is particularly important to ensuring that health promotion activities offered are community relevant (Kruger et al., 2012). Hypothetically, creating a partnership with local bicycling promotion groups and offering bike education classes for families and the community may be an excellent partnership in a bikefriendly community, but not as strong where safe biking opportunities are less abundant. The ability of the community to engage in youth physical activity promotion is highly dependent on the family context and how involved families are in the community (Finkelstein, Petersen, \& Schottenfeld, 2017). Unfortunately, community facility or activity designers often fail to solicit parent input or feedback (Finkelstein et al., 2017). For many communities, the following are inhibitors to successfully engaging youth in physical activity: (a) lack of affordable options, (b) traffic safety, (c) exposure to illicit activity in public spaces, (d) limited access to high-quality facilities, (e) transportation concerns, (f) lack of program availability, and (g) lack of information about programs offered (Finkelstein et al., 2017).

The presence of any of the previously mentioned barriers may cause community spaces and programs to be underutilized by students and their families within the setting of OLPE. For instance, restricted access to school facilities for physical activity engagement and OLPE instructors' inability to assure the safety of community facilities and equipment were noted challenges to OLPE students' physical activity engagement within the community (Mosier \& Lynn, 2012). Inaccessible community facilities and equipment were also significant barriers to learning within another OLPE program, in which only $68.9 \%$ of OLPE students surveyed agreed facilities were available for their physical activity engagement every week (Harris \& Metzler, 2019). Identifying which barriers exist, as well as mapping the assets that a community offers, are important steps that should be taken to inform community planning and implementation of initiatives to support youth physical activity (Allar et al., 2017).

\section{The CSPAP Outcomes Framework}

Through the OLPE support system, it can be surmised that students will demonstrate targeted physical activity behaviors within the
CSPAP outcomes framework, which consists of the physical education content standards and the youth physical activity guidelines. The student must be considered an active member and communicator in the activities; investments; decisions; and connections that schools, families, and communities promote for the student's success (Epstein, 2010). Student-related factors that warrant attention include the student's physical education and physical activity abilities (e.g., physical, mental, and socialemotional); interests and motivation; and OLPE technical skills and abilities. Where disparities may be most pronounced is in the extent to which students with disabilities will be able to use OLPE for achieving physical education standards and meeting physical activity guidelines. There are nearly seven million students with disabilities in the United States (Pew Research Center, 2020). This group makes up nearly $14 \%$ of national public school enrollment and has increased by $11 \%$ between the years 2000 and 2018 (Hussar et al., 2020).

Students with disabilities encounter challenges as they seek to engage with online curricula, irrespective of whether the mode of delivery is supplemental, blended, or full time (Basham et al., 2015). As reported by various outlets (Camera, 2020), the COVID19 pandemic has accentuated this challenge for students with disabilities. A poll of 2,400 parents in New York and California from March, 25 to April, 1 noted that $27 \%$ and $24 \%$ of parents respectively felt that schools were providing adequate online instructional material for their students (Education Trust-West, 2020). While online opportunities can provide significant opportunities for many people with disabilities, Kent (2015) notes that disability is activated differently in these formats. Impairments related to vision, cognition, hearing, and manual dexterity, for example, could be significantly disabling depending on how the use of print, video, and audio is used online.

These perspectives underscore the necessity for a more equitybased approach to constructing online education for learners with disabilities. Literature has yet to fully conceptualize this, choosing instead to highlight interventions that consider the notion of universal design as a "retrofit" to existing courses (McManus, Dryer, \& Henning, 2017; Kinash, Crichton, \& Kim-Rupnow, 2004). Ellis and Kent (2011) advocate for disability access built into online design processes at the outset to avoid pitfalls and shortterm changes that are made because of political pressures. In developing online learning modalities, Kent (2015) also suggests that designers reflect on the social model of disability. This model moves the narrative away from a person with a disability being seen as "having something wrong" and needing to be "fixed" to an examination of how modern life is constructed in a way to exclude or restrict people with disabilities (Oliver, 1990).

\section{Implications for Practice}

Physical education teacher education (PETE) faculty are positioned to play leading roles in strengthening OLPE and supporting CSPAP goals by addressing many of the factors identified in Figure 2. Establishing partnerships between university programs and local schools is a long-standing tradition in the work of PETE faculty, both in terms of fostering authentic field experiences and internship placements for teacher candidates and conducting school-based research. In the COVID era and beyond, this work must continue with an increased focus on generating buy-in and advocacy from school administrators and other school staff for quality physical education and CSPAPs. Principals' involvement will likely be essential to maximizing the reach of physical 
education and daily physical activity promotion through the family and community engagement component of a CSPAP, given the principal's prominence and connectedness within school communities. At the elementary school level, the involvement of classroom teachers may be equally important. These teachers, with whom children spend the majority of each school day, tend to develop the closest ties with families and harness the deepest insights into students' lives. Virtual teaching has opened new windows into students' home lives, and physical education teachers can improve their OLPE teaching effectiveness from gathering as much information as possible from other teachers about students' situations at home. PETE faculty should strive to give teacher candidates opportunities to communicate with school administrators about physical education programming and CSPAPs; learn the distinct professional roles of different administrators (e.g., principal, assistant principal, and district officials); and collaborate with both preservice and in-service classroom teachers to meet CSPAP goals.

Technology integration in preservice preparation must now incorporate learning experiences that focus on using various videoconferencing platforms (e.g., Microsoft Teams, Blackboard Collaborate, Zoom, and Webex); digital device options (e.g., different kinds of desktops, laptops, tablets, and smartphones) and a wide range of applications and software adopted by school districts. Proficiency with these tools is fundamental to OLPE delivery and has become imperative since the onset of the COVID-19 pandemic. Furthermore, teacher candidates should gain experience using these tools to teach and learn within urban, suburban, and rural settings to develop a "real world" appreciation of the digital divide and to create lesson plans that reflect a first-hand understanding of technological constraints placed on distance education. Beyond becoming proficient with various digital tools for OLPE, preservice physical education teachers also need experiences using different methods of virtual program delivery, including synchronous instruction, asynchronous instruction, and hybrid models of instruction that blend online learning with in-person learning. A well-prepared 21st century physical education teacher must feel comfortable teaching within any of these instructional approaches, in addition to being able to teach under traditional, 5 days a week, in-person conditions.

Professional development workshops, parent seminars, and open house/back-to-school nights (in person or virtual) present additional platforms for addressing key factors associated with successful OLPE delivery. PETE faculty and teacher candidates can speak at these events to raise awareness of the importance of physical education and physical activity to whole child health and development and provide school staff and parents with strategies to support OLPE, as well as be involved with a CSPAP more broadly. Such strategies can be based on the work of faculty and candidates to conduct needs assessments and perform asset mapping to identify the most pressing needs of students and families (e.g., increased access to the Internet, and more culturally relevant programming) and the existing resources available within school communities (e.g., local funding opportunities, outdoor spaces for practicing psychomotor skills, and being physically active) to support student learning, family and community engagement, physical education programming, and physical activity.

Increased research in the area of OLPE will be foundational to informing measures taken to increase understanding related to, and accountability for, the use of best practices in OLPE in both preservice teacher education and K-12 physical education. Sargent and Casey (2019) recommended taking an appreciative inquiry approach to conducting research on the use of digital technologies in physical education. Appreciative inquiry is a strength-based approach that focuses on the positive aspects of technology integration rather than focusing on deficits and limitations. Citing Cooperrider and Whitney (2001), Sargent and Casey describe a cyclical approach to appreciative inquiry research, which encompasses four steps: discover, dream, design, and destiny. Discovery entails identifying what makes the technology appealing. The second step, dreaming, involves imagining what the technology could look like in the future. During the design step, the features needed to realize the dream are fleshed out. Finally, destiny brings the process back full circle with a focus on further transformation of the technology via the creation of new objectives for change. This research approach can serve as a valuable guide for PETE faculty seeking to coalesce and advance the best qualities of current OLPE technologies and practices in order to produce next generation resources for the profession.

\section{Conclusion}

The COVID-19 pandemic has accelerated the need for effective integration of novel approaches to physical education in the presence of wide scale school closures and limited opportunities for in-person P-12 instruction. In this article, the authors have presented OLPE as a viable alternate mechanism for equitable physical activity promotion among youth in the current climate, drawing from the synergy of the CSPAP framework. To help teacher educators and researchers conceptualize the integration of OLPE with CSPAPs, it is purported that standards-based physical education programs can serve to promote physical activity for all youth in school, community, and home settings with the support of OLPE tools. Similarly, the goals and expectations for high-quality physical education instruction and delivery should apply to the development of successful OLPE platforms that strive to make physical activity programming equitable, developmentally appropriate, and equally accessible, accounting for unique factors of effective OLPE access and delivery at the student, family, school, and community levels. In this sense, OLPE, through capitalizing on the inherent interconnectedness between the school, digital technologies, physical education, the family, the community, and the student can serve to support CSPAP goals. Building from the schematic presented in this article, a natural next step is to develop learning experiences in PETE that focus on OLPE competency building, needs assessment, and resource optimization in the family and community contexts. Concurrently, research should examine the potential for preparing $\mathrm{P}-12$ school professionals (e.g., physical education teachers and teacher educators) in successful practices for OLPE delivery and assess students' learning, physical activity, and related health outcomes.

\section{References}

Allar, I., Elliott, E., Jones, E., Kristjansson, A.L., Taliaferro, A., \& Bulger, S.M. (2017). Involving families and communities in CSPAP development using asset mapping. Journal of Physical Education, Recreation \& Dance, 88(5), 7-14. doi:10.1080/07303084.2017.1280439

Anderson, C.B., Hughes, S.O., \& Fuemmeler, B.F. (2009). Parent-child attitude congruence on type and intensity of physical activity: Testing multiple mediators of sedentary behavior in older children. Health Psychology, 28(4), 428-438. PubMed ID: 19594267 doi:10.1037/ a0014522 
Basham, J.D., Stahl, S., Ortiz, K., Rice, M.F., \& Smith, S. (2015). Equity matters: Digital \& online learning for students with disabilities. Lawrence, KS: Center on Online Learning and Students with Disabilities.

Bodsworth, H., \& Goodyear, V.A. (2017). Barriers and facilitators to using digital technologies in the Cooperative Learning model in physical education. Physical Education and Sport Pedagogy, 22(6), 563-579. doi:10.1080/17408989.2017.1294672

Brown, H.E., Atkin, A.J., Wong, P.G., Chinapaw, M.J.M., \& van Sluijs, E.M.F. (2016). Family-based interventions to increase physical activity in children: A systematic review, meta-analysis, and realist synthesis. Obesity Reviews, 18(4), 491-494. doi:10. 1111/obr.12493

Buschner, C. (2006). Online physical education: Wires and lights in a box. Journal of Physical Education, Recreation \& Dance, 77(2), 3-8. doi:10.1080/07303084.2006.10597818

Camera, L. (2020). Schools struggle to educate students with disabilities amid pandemic. Retrieved from https://www.usnews.com/news/ education-news/articles/2020-04-15/schools-struggle-to-educatestudents-with-disabilities-amid-pandemic

Carson, R.L., Castelli, D.M., Beighle, A., \& Erwin, H. (2014). Schoolbased physical activity promotion: A conceptual framework for research and practice. Childhood Obesity, 10(2), 100-106.

Carson, R.L., \& Webster, C.A. (2020). Comprehensive school physical activity programs: Putting research into evidence-based practice. Champaign, IL: Human Kinetics.

Casey, A., Goodyear, V.A., \& Armour, K.M. (2017). Digital technologies and learning in physical education: Pedagogical cases. Milton Park, Abington, Oxfordshire: Routledge.

Centeio, E.E. (2017). The have and have-nots: An ever-present digital divide. Journal of Physical Education, Recreation \& Dance, 88(6), 11-12. doi:10.1080/07303084.2017.1331643

Centers for Disease Control and Prevention. (2012). Parent engagement: Strategies for involving parents in school health. Atlanta, GA: U.S. Department of Health and Human Services.

Centers for Disease Control and Prevention. (2019). Increasing physical education and physical activity: A framework for schools. Atlanta, GA: Centers for Disease Control and Prevention, U.S. Department of Health and Human Services

Chen, S., \& Gu, X. (2018). Toward active living. Comprehensive school physical activity program research and implications. Quest, 70(2), 191-212. doi:10.1080/00336297.2017.1365002

Cipriani, K., Richardson, C., \& Roberts, G. (2012). Family and community involvement in the comprehensive school physical activity program. Journal of Physical Education, Recreation \& Dance, 83(7), 20-26. doi:10.1080/07303084.2012.10598807

Cooperrider, D.L., \& Whitney, D. (2001). A positive revolution in change: Appreciative inquiry. Public Administration and Public Policy, 87, 611-630.

Daum, D.N. (2020). Thinking about hybrid or online learning in physical education? Start here! Journal of Physical Education, Recreation \& Dance, 91(1), 42-44. doi:10.1080/07303084.2020.1683387

Daum, D.N., \& Buschner, C. (2014). Research on teaching blended and online physical education. In R.E. Ferdig\& K. Kennedy (Eds.), Handbook of Research on K-12 Online and Blended Learning (1st ed., pp. 201-222). Pittsburg, PA: ETC Press.

Daum, D.N., \& Buschner, C. (2018). Research on teaching K-12 online physical education. In K. Kennedy\& R.E. Ferdig (Eds.), Handbook of Research on K-12 Online and Blended Learning (2nd ed., pp. 321334). Pittsburg, PA: ETC Press.

Daum, D.N., \& Woods, A.M. (2015). Physical education teacher educator's perceptions toward understanding of $\mathrm{K}-12$ online physical education. Journal of Teaching in Physical Education, 34(4), 716-724. doi:10.1123/jtpe.2014-0146

Davison, K.K., Jurkowski, J.M., Li, K., Kranz, S., \& Lawson, H.A. (2013). A childhood obesity intervention developed by families for families: Results from a pilot study. International Journal of Behavioral Nutrition and Physical Activity, 10(1), 3. doi:10.1186/ 1479-5868-10-3

Dewey, J. (1916). Democracy and education: An introduction to the philosophy of education. New York, NY: Macmillan.

Digital Learning Collaborative. (2020). Snapshot 2020: A review of K-12 online, blended, and digital learning. Retrieved from https://static1. squarespace.com/static/5a98496696d4556b01f86662/t/5e61341d 879e630db4481a01/1583428708513/DLC-KP-Snapshot2020.pdf

Education Trust-West. (2020). California parent poll: COVID-19 and school closures. Retrieved from https://west.edtrust.org/ca-parentpoll-covid-19-and-school-closures/

Egan, C.A., \& Miller, M. (2019). Family and community involvement to increase physical activity as part of a CSPAP. Journal of Physical Education, Recreation \& Dance, 90(1), 39-45. doi:10.1080/ 07303084.2018 .1535342

Ellis, K., \& Kent, M. (2011). Disability and new media. New York, NY: Routledge.

Epstein, J.L. (2010). School/family/community partnerships: Caring for the children we share. Phi Delta Kappan, 92(3), 81-96. doi:10.1177/ 003172171009200326

Erwin, H., Beighle, A., Carson, R.L., \& Castelli, D.M. (2013). Comprehensive school-based physical activity promotion: A review. Quest, 65(4), 412-428. doi:10.1080/00336297.2013.791872

Evergreen Education Group. (2016). Keeping pace with K-12 online learning. Retrieved from https://static1.squarespace.com/static/59381b9a 17bffc68bf625df4/t/593efc779f745684e6ccf4d8/1497300100709/ EEG_KP2016-web.pdf/

Finkelstein, D.M., Petersen, D.M., \& Schottenfeld, L.S. (2017). Promoting children's physical activity in low-income communities in Colorado: What are the barriers and opportunities? Preventing Chronic Disease, 14, E134. doi:10.5888/pcd14.170111

Fishbane, L., \& Tomer, A. (2020). As classes move online during COVID19, what are disconnected students to do? Brookings. Retrieved from https://www.brookings.edu/blog/the-avenue/2020/03/20/as-classesmove-online-during-covid-19-what-are-disconnected-students-to-do/

The Foundation for Blended and Online Learning. (2018). Digital learning strategies for rural America: A scan of policy and practice in $K-12$ education. Retrieved from https://files.eric.ed.gov/fulltext/ ED588911.pdf.

Glowacki, E.M., Centeio, E.E., Van Dongen, D.J., Carson, R.L., \& Castelli, D.M. (2016). Health promotion efforts as predictors of physical activity in schools: An application of the diffusion of innovations model. Journal of School Health, 86(6), 399-406. doi:10.1111/ josh. 12390

Harris, M.T., \& Metzler, M. (2019). Online personal fitness course alignment with national guidelines for online physical education. Journal of Teaching in Physical Education, 38(3), 174-183. doi:10. 1123/jtpe.2018-0169

Hastie, P.A. (2017). Revisiting the national physical education content standards: What do we really know about our achievement of the physically educated/literate person? Journal of Teaching in Physical Education, 36(1), 3-19. doi:10.1123/jtpe.2016-0182

Henderson, A.T., \& Berla, N. (1994). A new generation of evidence: The family is critical to student achievement (Report No. ISBN-0934460-41-8). Washington, DC: National Committee for Citizens in Education. (ERIC Document Reproduction Service No. ED 375968) 
Hollis, J.L., Sutherland, R., Williams, A.J., Campbell, E., Nathan, N., Wolfenden, L., ... Wiggers, J. (2017). A systematic review and meta-analysis of moderate-to-vigorous physical activity levels in secondary school physical education lessons. International Journal of Behavioral Nutrition and Physical Activity, 14(1), 52. doi:10.1186/ s12966-017-0504-0

Hollis, J.L., Williams, A.J., Sutherland, R., Campbell, E., Nathan, N., Wolfenden, L., ... Wiggers, J. (2016). A systematic review and meta-analysis of moderate-to-vigorous physical activity levels in elementary school physical education lessons. Preventive Medicine, 86, 34-54. PubMed ID: 26592691 doi:10.1016/j.ypmed.2015.11.018

Huerta, L., Shafer, S.R., Barbour, M.K., Miron, G., \& Gulosino, C. (2015). Virtual schools in the U.S. 2015: Politics, performance, policy, and research evidence. Retrieved from http://nepc.colorado.edu/ publication/virtual-schools-annual-2015

Hussar, B., Zhang, J., Hein, S., Wang, K., Roberts, A., Cui, J., ... Dilig, R. (2020). The condition of education 2020 (NCES 2020-144). Washington, DC: National Center for Education Statistics, U.S. Department of Education. Retrieved from https://nces.ed.gov/ pubsearch/pubsinfo.asp?pubid=2020144

Hutchens, A., \& Lee, R.E. (2018). Parenting practices and children's physical activity: An integrative review. The Journal of School Nursing, 34(1), 68-85. PubMed ID: 28631518 doi:10.1177/ 1059840517714852

Institute of Medicine. (2013). Educating the study body: Taking physical activity and physical education to school. Washington, DC: National Academic Press.

Kane, J.J. (2004). The dog ate my disk: Teacher and student perspectives of an online personal fitness course. Florida Alliance for Health, Physical Education, Recreation, and Dance Journal, 2, 8-12.

Kent, M. (2015). Disability and eLearning: Opportunities and barriers. Disability Studies Quarterly, 35(1). Retrieved from https://dsq-sds. org/article/view/3815/3830

Killian, C.M., Kinder, C.J., \& Woods, A.M. (2019). Online and blended learning in K-12 physical education: A scoping review. Kinesiology Review, 8(2), 110-129. doi:10.1123/kr.2019-0003

Killian, C.M., Woods, A.M., Graber, K.C., \& Templin, T. (2020). Factors associated with high school physical education teachers' adoption of a supplemental online instructional system (iPE). Journal of Teaching in Physical Education, 40(1), 136-145. doi:10.1123/jtpe. 2019-0188

Kimiecik, J.C., \& Horn, T.S. (1998). Parental beliefs and children's moderate-to-vigorous physical activity. Research Quarterly for Exercise and Sport, 69(2), 163-175. doi:10.1080/02701367.1998. 10607681

Kinash, S., Crichton, S., \& Kim-Rupnow, W.S. (2004). A review of 20002003 literature at the intersection of online learning and disability. American Journal of Distance Education, 18(1), 5-19. doi:10.1207/ s15389286ajde1801_2

Kirk, D. (1999). Physical culture, physical education and relational analysis. Sport, Education and Society, 4(1), 63-73. doi:10.1080/ 1357332990040105

Kooiman, B.J. (2017). Moving online physical education from oxymoron to efficacy. Sport, Education and Society, 22(2), 230-246. doi:10. 1080/13573322.2015.1015978

Kruger, T.M., Swanson, M., Davis, R.E., Wright, S., Dollarhide, K., \& Schoenberg, N.E. (2012). Formative research conducted in rural Appalachia to inform a community physical activity intervention. American Journal of Health Promotion, 26(3), 143-151. PubMed ID: 22208411 doi:10.4278/ajhp.091223-QUAL-399

Lane, C., Carson, V., Morton, K., Reno, W., Wright, C., Predy, M., \& Naylor, P. (2020). A real world feasibility trial of the PLAYshop:
A brief intervention to facilitate parent engagement in developing their child's physical literacy. Manuscript under review.

Lawson, H.A. (Ed.). (2018). Redesigning physical education: An equity agenda in which every child matters. New York, NY: Routledge.

Lindsay, A., Sussner, K., Kim, J., \& Gortmaker, S. (2006). The role of parents in preventing childhood obesity. The Future of Children, 16(1), 169-186. PubMed ID: 16532663 doi:10.1353/foc.2006. 0006

Lindsay, A.C., Wasserman, M., Muñoz, M.A., Wallington, S.F., \& Greaney, M.L. (2018). Examining influences of parenting styles and practices on physical activity and sedentary behaviors in Latino children in the United States: Integrative review. JMIR Public Health and Surveillance, 4(1), e14. PubMed ID: 29382629 doi:10.2196/ publichealth.8159

Locke, L.F. (1997). Minutes of the commodore club: Even luddites chat on the internet. Quest, 49(3), 270-279.

McManus, D., Dryer, R., \& Henning, M. (2017). Barriers to learning online experienced by students with a mental health disability. Distance Education, 38(3), 336-352. doi:10.1080/01587919.2017. 1369348

McWilliams, S.R., Bulger, S., Keath, A., \& Elliott, E. (2020). The fit family challenge: A county-wide, web-based, physical activity initiative. Journal of Physical Education, Recreation \& Dance, 91(3), 35-39. doi:10.1080/07303084.2019.1705212

Mohnsen, B. (2012). Implementing online physical education, Journal of Physical Education, Recreation \& Dance, 83(2), 42-47. doi:10.1080/ 07303084.2012.10598727

Moore, L.L., Lombardi, D.A., White, M.J., Campbell, J.L., Oliveria, S.A., \& Ellison, R.C. (1991). Influence of parents' physical activity levels on activity levels of young children. The Journal of Pediatrics, 118(2), 215-219. PubMed ID: 1993947 doi:10.1016/S00223476(05)80485-8

Mosier, B., \& Lynn, S. (2012). An initial exploration of a virtual personal fitness course. Online Journal of Distance Learning Administration, 15(3). Retrieved from $\sim$ https://www.westga.edu/ distance/ojdla/fall153/ mosier_lynn $153 . \mathrm{html}$

Oliver, M. (1990). The politics of disablement. London, UK: Macmillan Education.

Orendorff, K., Webster, C.A., Mindrila, D., Cunningham, K. M. W., Doutis, P., Dauenhauer, B., \& Stodden, D.F. (2020). Principals' involvement in comprehensive school physical activity programmes: A social-ecological perspective. European Physical Education Review. doi:10.1177/1356336X20976687.

Parker, M., MacPhail, A., O’Sullivan, M., Ní Chróinín, D., \& McEvoy, E. (2018). Drawing conclusions: Primary school children's construction of school physical education and physical activity opportunities outside of school. European Physical Education Review, 24(4), 449-466. doi:10.1177/1356336X16683898

Pérusse, L., Leblanc, C., \& Bouchard, C. (1988). Familial resemblance in lifestyle components: Results from the Canada fitness survey. Canadian Journal of Public Health, 79(3), 201-205. PubMed ID: 3401837

Pew Research Center. (2020). As schools shift to online learning amid pandemic, here's what we know about disabled students in the U.S. Retrieved from https://www.pewresearch.org/fact-tank/2020/04/23/ as-schools-shift-to-online-learning-amid-pandemic-heres-what-weknow-about-disabled-students-in-the-u-s/

Ransdell, L.B., Eastep, E., Taylor, A., Oakland, D., Schmidt, J., MoyerMileur, L., \& Shultz, B. (2003). Daughters and mothers exercising together (DAMET): Effects of home-and university-based interventions on physical activity behavior and family relations. American Journal of Health Education, 34(1), 19-29. doi:10.1080/19325037. 2003.10603521 
Rhodes, R.E., Guerrero, M.D., Vanderloo, L.M., Barbeau, K., Birken, C.S., Chaput, J., ... Tremblay, M.S. (2020). Development of a consensus statement on the role of the family in the physical activity, sedentary, and sleep behaviours of children and youth. International Journal of Behavioral Nutrition and Physical Activity, 17(1), 74. doi:10.1186/s12966-020-00973-0

Riddlesden, D., \& Singleton, A.D. (2014). Broadband speed equity: A new digital divide? Applied Geography, 52, 25-33. doi:10.1016/j.apgeog. 2014.04.008

Rose, R. (2014). Access and equity for all learnings in online and blended education. International Association for K-12 Online Learning. Retrieved from https://files.eric.ed.gov/fulltext/ED561307.pdf

Rose, R., \& Blomeyer, R. (2007). Access and equity in online classes and virtual schools. International Association for $\mathrm{K}-12$ Online Learning. Retrieved from http://www.inacol.org/wpcontent/uploads/2015/02/ iNACOL_AccessEquity_2007.pdf

Sallis, J.F., Patterson, T.L., Buono, M.J., Atkins, C.J., \& Nader, P.R. (1988). Aggregation of physical activity habits in Mexican-American and Anglo families. Journal of Behavioral Medicine, 11(1), 31-41. PubMed ID: 3367370 doi:10.1007/BF00846167

Sargent, J., \& Casey, A. (2019). Appreciative inquiry for physical education and sport pedagogy research: A methodological illustration through teachers' use of digital technology. Sport, Education and Society, 26(1), 45-57. doi:10.1080/13573322.2019.1689942

SHAPE America (2015). Comprehensive school physical activity programs: Helping all students log 60 minutes of physical activity each day. [Position statement]. Reston, VA: Author.

SHAPE America (2018). Guidelines for K-12 Online Physical Education. [Guidance document]. Reston, VA: Author.

Smith, A. (2015). The smartphone difference. Retrieved from http://www. pewinternet.org/2015/04/01/us-smartphone-use-in-2015/
U.S. Department of Health and Human Services. (2018). Physical activity guidelines for Americans (2nd ed.). Washington, DC: Author.

Velde, G.T., Lubrecht, J., Arayess, L., Loo, C.V., Hesselink, M., Reijnders, D., \& Vreugdenhil, A. (2020). The impact of the COVID-19 pandemic on physical activity behavior and screen time in Dutch children during and after school closures. The Lancet. Advance online publication. doi:10.2139/ssrn.3714619

Webster, C.A., Beets, M.W., Weaver, R.G., Vazou, S., \& Russ, L. (2015). Rethinking recommendations for implementing comprehensive school physical activity programs: A partnership model. Quest, 67(2), 185-202. doi:10.1080/00336297.2015.1017588

Webster, C.A., Glascoe, G., Moore, C., Dauenhauer, B., Egan, C.A., Russ, L.B., ... Buschmeier, C. (2020). Recommendations for administrators' involvement in school-based health promotion: A scoping review. International Journal of Environmental Research and Public Health, 17(17), 6249. doi:10.3390/ijerph 17176249

Webster, C.A., Rink, J.E., Carson, R.L., Moon, J., \& Geaudrault, K.L. (2020). The comprehensive school physical activity program model: A proposed illustrative supplement to help move the needle on youth physical activity. Kinesiology Review, 9(2), 112-121. doi:10.1123/kr. 2019-0048

Williams, L., Martinasek, M., Karone, K., \& Sanders, S. (2020). High school students' perceptions of traditional and online health and physical education courses. Journal of School Health, 90(3), 234 244. doi:10.1111/josh.12865

Xiang, M., Zhang, Z., \& Kuwahara, K. (2020). Impact of COVID19 pandemic on children and adolescents' lifestyle behavior larger than expected. Progress in Cardiovascular Diseases, 63(4), 531-532. PubMed ID: 32360513 doi:10.1016/j.pcad.2020.04.013 